\title{
Effect of ozonated water on the surface roughness of dental stone casts
}

\author{
Ryo NISHIKIORI ${ }^{1}$, Masahiko SAWAJIRI ${ }^{2}$, Tetsuji OKUDA ${ }^{3,4}$, Atsunori OTOSHI ${ }^{3}$, Kotaro WATANABE ${ }^{1}$, Isao HIRATA ${ }^{1}$, \\ Wataru NISHIJIMA ${ }^{3}$ and Masayuki OKAZAKI ${ }^{1}$ \\ ${ }^{1}$ Department of Biomaterials Science, Graduate School of Biomedical Sciences, Hiroshima University, 1-2-3 Kasumi, Minami-ku, Hiroshima 734- \\ 8553, Japan \\ ${ }^{2}$ Department of Oral and Maxillofacial Radiology, Graduate School of Biomedical Sciences, Hiroshima University, 1-2-3 Kasumi, Minami-ku, Hiroshima \\ 734-8553, Japan \\ ${ }^{3}$ Environmental Research and Management Center, Hiroshima University, 1-5-3 Kagamiyama, Higashi-hiroshima 739-8527, Japan \\ ${ }^{4}$ Faculty of Science and Technology, Ryukoku University, 1-5 Yokotani, Ooe-cho, Seta, Otsu, Shiga 520-2194, Japan \\ Corresponding author, Ryo NISHIKIORI; E-mail: rnishikiori8@hiroshima-u.ac.jp
}

\begin{abstract}
Infection control of dental stone cast is an important issue. Ozone is effective for disinfection against microorganisms and inactivation of viruses. However, there is little information regarding the use of ozone. We prepared 4 types of gypsum specimens and 3 types of disinfectants (4-5 ppm Ozonated water [OZW], 2\% glutaraldehyde [GL], and 1\% sodium hypochlorite [SH]). Gypsum specimens were immersed in each disinfectant for 5 and $10 \mathrm{~min}$, and surface roughness was then examined using laser scanning microscopy. Surface microstructure was investigated using scanning electron microscopy. Immersion of gypsum specimens in SH, GL, and OZW increased the surface roughness to a maximum of $1.04,0.37$, and $0.30 \mu \mathrm{m}$, respectively, based on the difference between the average values of surface roughness before and after the disinfection procedure. The effects of OZW and GL were comparable. OZW is useful as a candidate for relatively safe disinfection of material for dental stone casts.
\end{abstract}

Keywords: Ozonated water, Dental stone cast, Disinfectant material, Glutaraldehyde, Sodium hypochlorite

\section{INTRODUCTION}

Infection control has become an important issue for dental clinics and dental laboratory personnel in recent years. Dental prostheses, appliances, and other items (e.g., impressions, occlusal rims, and bite registrations) become contaminated with the patient's saliva, bacterial plaques, and blood. Patients at the dental clinic and dental healthcare personnel can be exposed to viruses and bacteria ${ }^{1-3)}$.

Maintaining the surface quality of impressions made with irreversible hydrocolloid impression materials and disinfecting them are difficult ${ }^{4,5}$. Dental prostheses, dental stone casts, or impressions sent to laboratories from dental clinics may be contaminated with microorganisms from patients' saliva and blood ${ }^{6-8)}$. As a countermeasure against infectious diseases, a method of immersing a dental stone cast in a disinfectant solution and disinfecting it has been investigated ${ }^{9,10)}$. However, these dental stone cast disinfection processes increase the surface roughness of the dental stone cast ${ }^{9,11,12)}$.

Various studies have been conducted on disinfection of dental stone casts. Glutaraldehyde (GL) has gained wide acceptance as a high-level disinfectant and chemical bactericide ${ }^{13}$. GL and sodium hypochlorite (SH) have been studied as dental stone cast disinfectants $\mathbf{s}^{9,10)}$. However, there are concerns regarding the effect of GL on human health ${ }^{14}$. Methods for heating disinfectants for dental stone models using microwaves have been investigated ${ }^{15}$. Additionally, ozonated water (OZW) has been investigated in various fields worldwide ${ }^{16-18)}$. Previous study reported that OZW for disinfecting dental units $^{17)}$, dental impressions ${ }^{19)}$, dental plates ${ }^{20)}$ and dental surgery material ${ }^{21)}$ was potency enough.

Ozone gas is produced when $\mathrm{O}_{2}$ is energized and split into 2 monatomic $\left(\mathrm{O}_{1}\right)$ molecules. These monatomic oxygen molecules then collide with $\mathrm{O}_{2}$ molecules to form ozone $\left(\mathrm{O}_{3}\right)$. Therefore, ozone consists of $\mathrm{O}_{2}$ with a loosely bonded third oxygen atom that is readily available to attach to and oxidize molecules ${ }^{13)}$.

OZW has a strong oxidizing potential and is effective for disinfection against microorganisms and inactivation of viruses ${ }^{13,18,22)}$. However, there is little information on the effect of OZW on surface roughness of dental stone casts. Therefore, we investigated the effects of OZW on surface roughness of dental stone casts from the viewpoint of biomaterial science as a disinfectant material.

\section{MATERIALS AND METHODS}

\section{OZW preparation}

Ozone gas was produced from 99.5\% oxygen gas by an ozone generator (Prity ozone, Fuji Electric, Mie, Japan). An ozone-oxygen mixture of gas was generated by an electrical discharge on $99.5 \%$ oxygen gas. OZW was prepared by bubbling ozone gas (ozone gas concentration of $1 \times 10^{2} \mathrm{mg} / \mathrm{L}$ ) through ultrapure water to prepare a concentration of $3-4 \times 10 \mathrm{mg} / \mathrm{L}(3-4 \times 10 \mathrm{ppm})$ each time for experiments. Ozone concentrations in water were measured using indigo methods ${ }^{23}$. OZW was immediately diluted to the appropriate final concentration (4-5 $\mathrm{ppm})^{16,20)}$ with a total volume of $500 \mathrm{~mL}$ using ultrapure water before the experiment. To inhibit decomposition 
of OZW, all manipulations of OZW were performed with glassware or a glass beaker and covered with plastic wrap.

For comparison, $25 \%$ GL $\left(25 \% \mathrm{C}_{5} \mathrm{H}_{8} \mathrm{O}_{2}\right.$, Lot no EPH0574, Wako, Osaka, Japan) and 10\% SH solution $(10 \% \mathrm{NaOCl}$, Lot no A9049, Sigma-Aldrich, Tokyo, Japan) were used in this study. They were diluted using ultrapure water to $2 \%^{11,24)}$ and $1 \%^{11)}$, respectively, for disinfection of gypsum specimens immediately before use.

\section{Gypsum specimen preparation}

Four types of dental gypsum, the die stone New Fujirock (Lot no. 1003251, GC, Tokyo, Japan), Hybrid Rock (Lot no. 950, Noritake, Aichi, Japan), the dental stone New Plastone (Lot no. 1003151, GC), and Vel-Mix Classic (Lot no. 0-21090, Kerr, Orange, CA, USA) were used in this study. We prepared a stainless steel test die according to Japanese Industrial Standards (JIS) (T6505: 2005) as specified in the ISO Specification 1563. Silicone molds were replicated from the stainless steel test die using Duplicon (Lot no. 650852, Shofu, Kyoto, Japan). Custommade rubber molds (Kinki-rubber, Kyoto, Japan) were prepared to make gypsum specimens.

A silicone mold and a custom-made rubber mold were combined in this study to make the gypsum specimens (Fig. 1). Two specimens of approximately 11 (width) $\times 12$ (length) $\times 3$ (thickness) $\mathrm{mm}$ were made by using a combined silicone mold and rubber mold per manipulation. Three horizontal lines and 2 vertical lines were transferred onto the gypsum specimens using a silicone mold taken from the stainless steel die. Intersection of these lines was used as a marker to measure the surface roughness of the same location as possible before and after disinfection (Fig. 2). Dental gypsum was mixed according to the manufacturer's instructions, poured into the combined rubber mold, and separated from the mold $1 \mathrm{~h}$ later. Gypsum specimens were prepared using multiple molds. Gypsum specimens were dried overnight at room temperature $\left(23 \pm 3^{\circ} \mathrm{C}\right)$.

\section{Disinfection procedure}

All disinfectants were prepared fresh each time for use. Four pieces of gypsum specimens were immersed with the disinfectant as carefully and as quickly as possible for the prescribed period of time. After disinfection, the gypsum specimen was rinsed with ultrapure water for $10 \mathrm{~s}$. The remaining water on the surface of the gypsum specimen was completely removed using a hand blower. Gypsum specimens were then dried overnight at room temperature $\left(23 \pm 3^{\circ} \mathrm{C}\right)$. Gypsum specimens without disinfection were only rinsed with ultrapure water for $10 \mathrm{~s}$. Thereafter, the remaining water on the surface of the gypsum specimen was completely removed using a hand blower. All of the experimental instruments used in this disinfection procedure were glassware and beakers covered with plastic wrap during the experiment.

Measurement of surface roughness of gypsum specimens Surface roughness of the gypsum specimens was

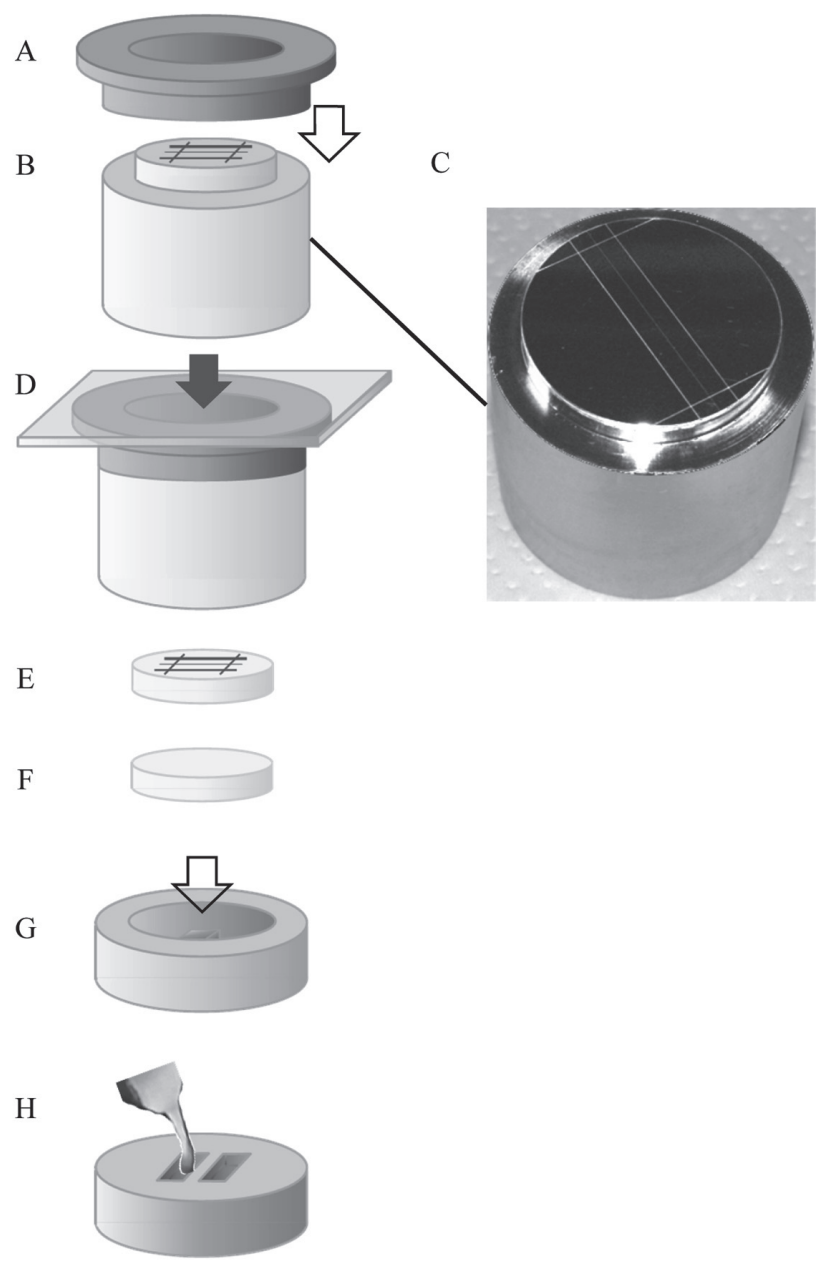

I

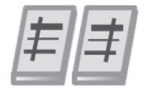

Fig. 1 Preparation of the specimens.

(A) The order-made rubber mold is set on the stainless steel test die. (B) Stainless steel test die: JIS T6505. (C) JIS T6505: 2005 test die. The stainless steel die has 3 horizontal lines and 2 vertical lines. These lines were used for a marker as a measurement location of surface roughness. (D) Duplicon is filled between the glass plate and rubber mold to make the silicone mold. (E) The duplicated silicone mold is removed from the rubber mold. (F) The silicone mold is flipped upside down. (G) The silicone mold is set in the rubber mold. (H) The rubber mold is flipped and the deaerated gypsum is poured. (I) After setting the gypsum, the gypsum specimens are removed from the rubber mold. The limitation value of surface roughness detection of the laser scanning microscopy is 0.01 $\mu \mathrm{m}$.

measured in almost the same location before and after disinfection of the gypsum specimen using laser scanning 
microscopy (VK-8500, Keyence, Osaka, Japan). The average surface roughness of gypsum specimens was calculated using the surface roughness of 4 independent, prearranged $100 \times 100 \mu \mathrm{m}^{2}$ areas (Fig. 2).

Subsequently, the difference (DIF) between the

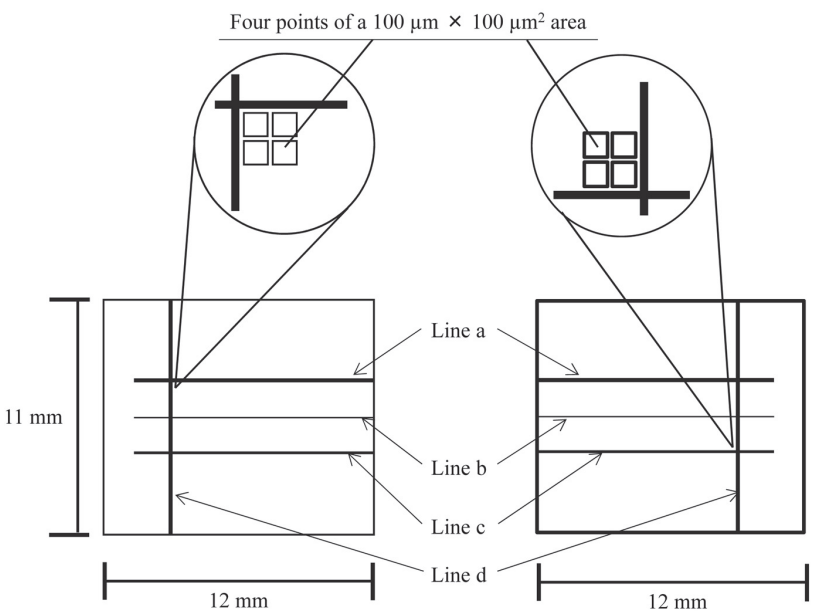

Fig. 2 Two types of $12 \times 11 \mathrm{~mm}^{2}$ specimens.

The width of lines a, b, c, and d is $75,50,75$, and $75 \mu \mathrm{m}$, respectively. The intersections of lines a and $\mathrm{d}$ and lines $\mathrm{c}$ and $\mathrm{d}$ on the gypsum specimens were used to decide the measurement location for surface roughness. surface roughness values of each before and after disinfection procedure were calculated and averaged.

Observation of the crystal structure using scanning electron microscopy (SEM)

To evaluate the effect of disinfectant on the crystal structure, the crystal structure of the gypsum specimen surface was observed using SEM (VE-8800, Keyence) with 3,000×magnification.

\section{Statistical analysis}

Descriptive statistics including the mean, standard deviation, and the minimum and maximum values were calculated for each test group. The data were analyzed by the two-tailed Student's $t$-test and Tukey's test. For detecting the time dependent effects, the specimen was disinfected for 5 or $10 \mathrm{~min}$ to compare the difference using $t$-test. To detect the statistically significant differences among the three disinfectants in the same gypsum specimen was used by Tukey's test. We compared OZW with SH and GL to evaluate effects of OZW. The critical value for rejecting the null hypothesis was set at $p<0.05$.

\section{RESULTS}

Changes in surface roughness by the disinfectants In this study, we evaluated the change in surface roughness at the same location as possible before

Table 1 Results of measured surface roughness of dental gypsum specimens

\begin{tabular}{|c|c|c|c|c|c|c|c|c|c|}
\hline \multicolumn{5}{|c|}{ New Fujirock } & \multicolumn{5}{|c|}{ Hybrid Rock } \\
\hline \multirow{2}{*}{ Time } & \multirow{2}{*}{ Disinfectant } & \multicolumn{2}{|c|}{ Surface roughness ${ }^{a}$} & \multirow{2}{*}{$\mathrm{DIF}^{\mathrm{b}}$} & \multirow{2}{*}{ Time } & \multirow{2}{*}{ Disinfectant } & \multicolumn{2}{|c|}{ Surface roughness ${ }^{a}$} & \multirow{2}{*}{$\mathrm{DIF}^{\mathrm{b}}$} \\
\hline & & Untreated & Treated & & & & Untreated & Treated & \\
\hline \multirow{3}{*}{$5 \mathrm{~min}$} & $\mathrm{OZW}$ & $1.20 \pm 0.15$ & $1.13 \pm 0.11$ & $-0.07 \pm 0.07$ & \multirow{3}{*}{$5 \min$} & $\mathrm{OZW}$ & $1.37 \pm 0.05$ & $1.40 \pm 0.29$ & $0.03 \pm 0.34$ \\
\hline & GL & $1.27 \pm 0.11$ & $1.31 \pm 0.15$ & $0.05 \pm 0.20$ & & GL & $1.36 \pm 0.08$ & $1.55 \pm 0.06$ & $0.18 \pm 0.11$ \\
\hline & $\mathrm{SH}$ & $1.32 \pm 0.25$ & $1.14 \pm 0.14$ & $-0.18 \pm 0.10$ & & $\mathrm{SH}$ & $1.14 \pm 0.02$ & $1.39 \pm 0.07$ & $0.25 \pm 0.07 \neg *$ \\
\hline \multirow{3}{*}{$10 \mathrm{~min}$} & OZW & $1.25 \pm 0.14$ & $1.34 \pm 0.31$ & $0.08 \pm 0.20$ & \multirow{3}{*}{$10 \mathrm{~min}$} & OZW & $1.50 \pm 0.06$ & $1.55 \pm 0.14$ & $0.05 \pm 0.11$ \\
\hline & GL & $1.14 \pm 0.09$ & $1.13 \pm 0.09$ & $-0.02 \pm 0.04$ & & GL & $1.00 \pm 0.09$ & $1.37 \pm 0.16$ & $0.37 \pm 0.10$ \\
\hline & $\mathrm{SH}$ & $1.31 \pm 0.14$ & $1.15 \pm 0.05$ & $-0.16 \pm 0.16$ & & $\mathrm{SH}$ & $1.04 \pm 0.05$ & $2.08 \pm 0.67$ & $1.04 \pm 0.63 \sqsupseteq$ \\
\hline \multicolumn{5}{|c|}{ New Plastone } & \multicolumn{5}{|c|}{ Vel-Mix Classic } \\
\hline \multirow{2}{*}{ Time } & \multirow{2}{*}{ Disinfectant } & \multicolumn{2}{|c|}{ Surface roughness ${ }^{a}$} & \multirow{2}{*}{$\mathrm{DIF}^{\mathrm{b}}$} & \multirow{2}{*}{ Time } & \multirow{2}{*}{ Disinfectant } & \multicolumn{2}{|c|}{ Surface roughness ${ }^{\mathrm{a}}$} & \multirow{2}{*}{$\mathrm{DIF}^{\mathrm{b}}$} \\
\hline & & Untreated & Treated & & & & Untreated & Treated & \\
\hline \multirow{3}{*}{$5 \mathrm{~min}$} & OZW & $1.01 \pm 0.14$ & $1.17 \pm 0.25$ & $0.17 \pm 0.16$ & \multirow{3}{*}{$5 \min$} & OZW & $1.06 \pm 0.07$ & $1.35 \pm 0.09$ & $0.30 \pm 0.07=$ \\
\hline & GL & $1.04 \pm 0.07$ & $1.29 \pm 0.19$ & $0.25 \pm 0.15$ & & GL & $1.25 \pm 0.07$ & $1.24 \pm 0.10$ & $0.00 \pm 0.06$ \\
\hline & $\mathrm{SH}$ & $1.19 \pm 0.11$ & $1.33 \pm 0.21$ & $0.14 \pm 0.22$ & & $\mathrm{SH}$ & $1.28 \pm 0.03$ & $1.53 \pm 0.19$ & $0.25 \pm 0.19$ \\
\hline \multirow{3}{*}{$10 \mathrm{~min}$} & OZW & $0.94 \pm 0.05$ & $1.19 \pm 0.06$ & $0.24 \pm 0.10$ & \multirow{3}{*}{$10 \mathrm{~min}$} & OZW & $1.26 \pm 0.07$ & $1.35 \pm 0.08$ & $0.10 \pm 0.03 \sqsupset^{*}$ \\
\hline & GL & $1.20 \pm 0.11$ & $1.40 \pm 0.01$ & $0.20 \pm 0.11$ & & GL & $1.33 \pm 0.18$ & $1.36 \pm 0.09$ & $0.03 \pm 0.11$ \\
\hline & $\mathrm{SH}$ & $1.26 \pm 0.11$ & $1.45 \pm 0.15$ & $0.19 \pm 0.15$ & & $\mathrm{SH}$ & $1.04 \pm 0.07$ & $1.48 \pm 0.12$ & $0.44 \pm 0.14$ \\
\hline
\end{tabular}

aData are expressed as mean for $n=4(\mu \mathrm{m})$ and mean \pm standard deviation; ${ }^{\mathrm{b}}$ Data are expressed as the mean of after calculated each difference (treated-untreated) (DIF) in $\mu \mathrm{m} .{ }^{*} p$-value $<0.05$. 

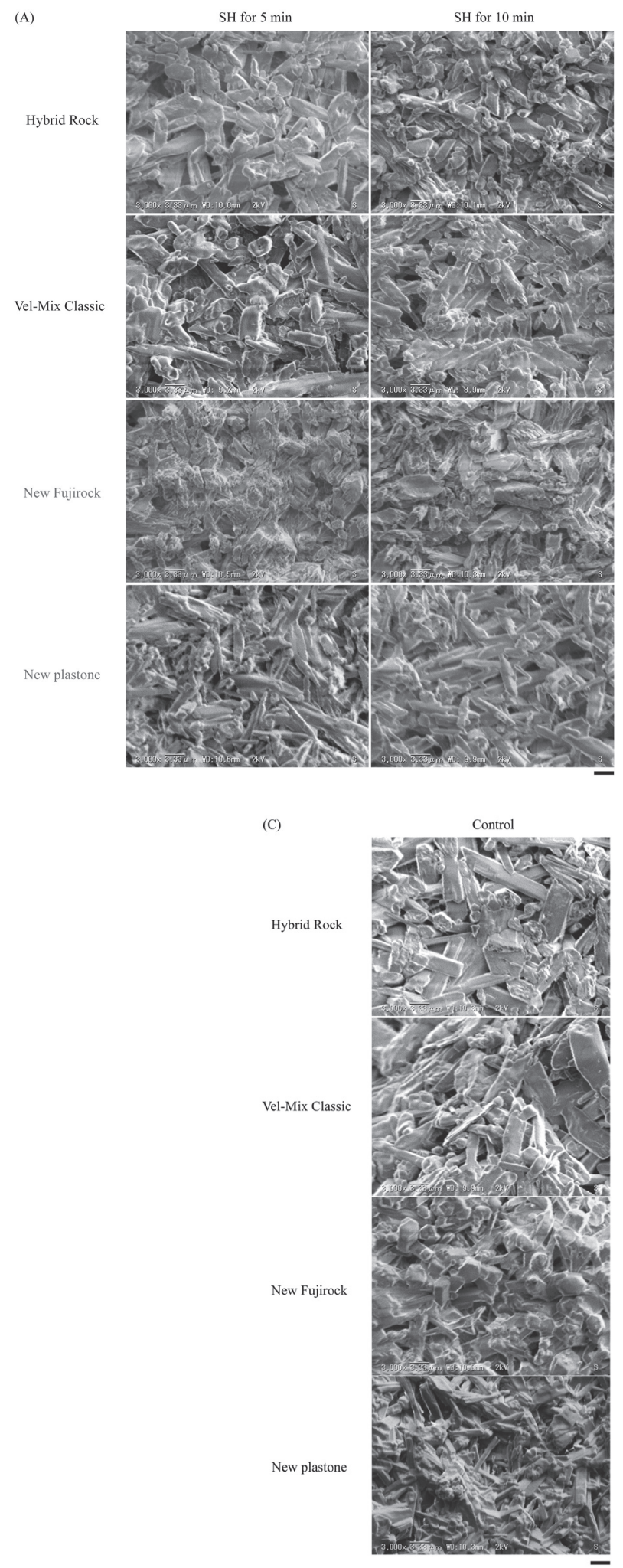

Fig. 3 Results of representative scanning electron micrographs of all gypsum specimens.

(A) Immersion in $1 \% \mathrm{SH}$ for 5 and $10 \mathrm{~min}$. (B) Immersion in $2 \%$ GL for 5 and $10 \mathrm{~min}$. (C) No immersion in any disinfectants as a control. Scale bars $=3.33 \mu \mathrm{m}$.

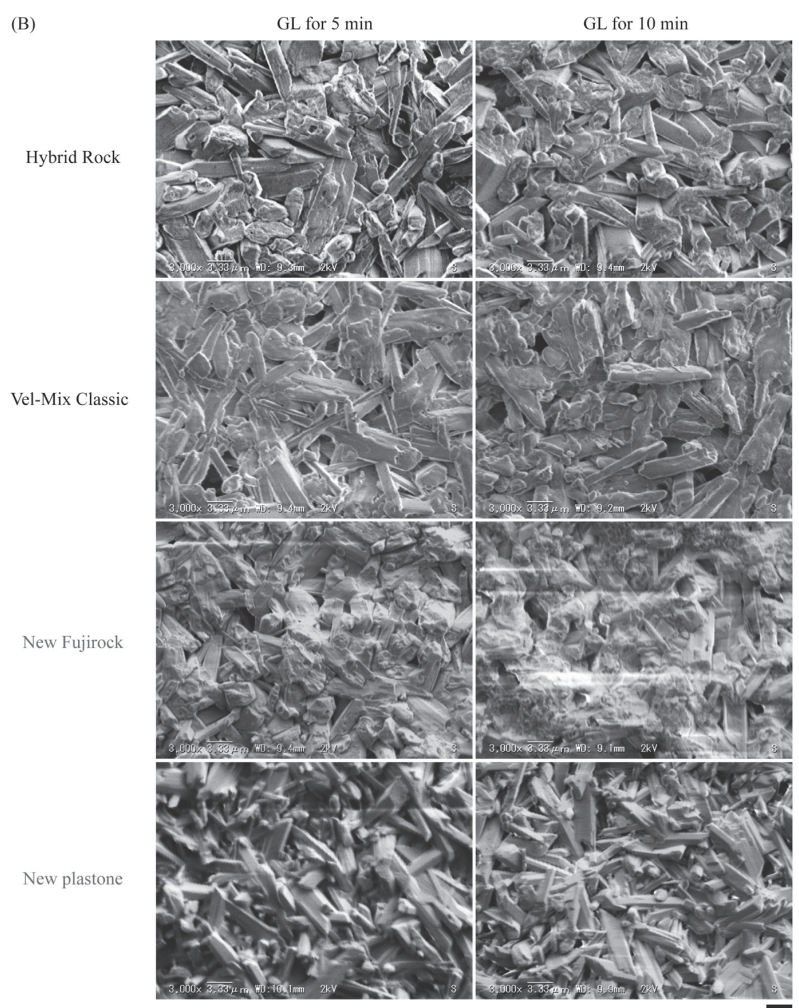

and after disinfection by using a mark on the gypsum specimen that was decided in advance. As a result, we were able to measure the surface roughness of a wide area by measuring 4 points in an independent $100 \times 100$ $\mu \mathrm{m}$ area for each specimen by using this method.

Surface roughness of all gypsum specimens was less than $2.08 \mu \mathrm{m}$ (Hybrid Rock, SH for $10 \mathrm{~min}$ ) after the disinfection procedure (Table 1). As shown in Table 1, tendency of the DIF value of New Plastone, Hybrid Rock, and Vel-Mix Classic immersed in $\mathrm{SH}$ increased in a time-dependent manner. Tendency of the DIF value of Hybrid Rock immersed in GL increased in a timedependent manner. The DIF value of Vel-mix Classic immersed in OZW significantly decreased in a timedependent manner. The DIF value of Vel-Mix Classic immersed in SH for 10 min was larger than immersed in GL and OZW. Similarly, the DIF value of Hybrid Rock immersed in OZW for 10 min was significantly smaller than immersed in $\mathrm{SH}$ for 10 min. The maximum DIF value of Hybrid Rock immersed in SH for 10 min was 1.04 $\mu \mathrm{m}$. The maximum DIF value of Hybrid Rock immersed in GL for 10 min was $0.37 \mu \mathrm{m}$. The maximum DIF value of Vel-Mix Classic immersed in OZW for 5 min was 0.30 $\mu \mathrm{m}$. DIF values for immersion in GL and OZW tended to be smaller than those for immersion in SH. DIF values for immersion in GL and OZW were similar. The average value of DIF for all gypsum specimens was 0.16 $\mu \mathrm{m}$. Some DIF values of New Fujirock were negative. This result did not occur in other gypsum specimens. 


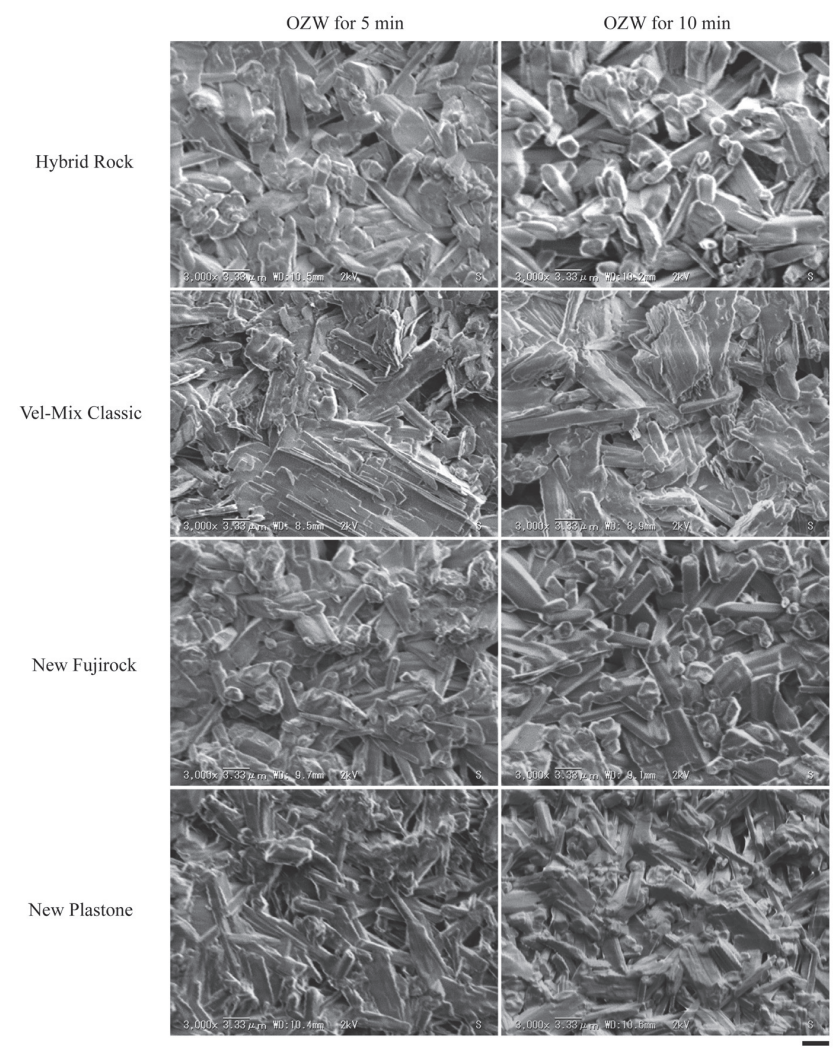

Fig. 4 Results of representative scanning electron micrographs of 4 types of dental gypsum specimens immersed in 4-5 ppm OZW for 5 and $10 \mathrm{~min}$. Scale bars $=3.33 \mu \mathrm{m}$.

\section{SEM observations of the crystal profiles}

SEM micrographs showed that immersion of Hybrid Rock and Vel-Mix Classic in $\mathrm{SH}$ affected the crystal grains of gypsum specimens in a time-dependent manner (Fig. 3A). In particular, immersion of Hybrid Rock and Vel-Mix Classic in SH for 5 or 10 min resulted in collapse of the shape of the rectangular crystal grains depending on the immersion time. This result was consistent with the trend in DIF values (Table 1). The crystal grains of New Fujirock and New Plastone immersed in $\mathrm{SH}$ for 5 and 10 min were well collapsed, we could not determine the breakage the crystal grains by time dependent manner. (Fig. 3A). However, the crystal grains of Hybrid Rock, New Fujirock and New Plastone immersed in GL did not show distinct breakage by time-dependent immersion (Fig. 3B). Weak, eroded crystal grain boundaries were observed on the surface of Vel-Mix Classic immersed in GL by SEM (Fig. 3B). The results of Vel-Mix Classic observation by SEM micrographs and DIF values (Table 1) were in good agreement. SEM micrographs showed that (Fig. 4), except for Hybrid Rock, all types of gypsum specimens that were immersed in OZW for 5 or $10 \mathrm{~min}$ did not show distinct breakage or erosion of crystal grains by time-dependent immersion. However, weak, eroded crystal grain boundaries were observed on the surface of Hybrid Rock.

\section{DISCUSSION}

Physical and chemical treatments, including the use of high temperatures, microwave irradiation, and chemical reagents, have been used for disinfection of dental stone casts $^{15,25)}$. Disinfection using OZW has also been studied in various fields ${ }^{16,17,21)}$.

In our study, except for New Fujirock, immersion of all gypsum specimens in $\mathrm{SH}$ suggested that the surface roughness of the gypsum specimens increased in a timedependent manner (Table 1). Hybrid Rock and Vel-Mix Classic immersed in GL showed a tendency for increased surface roughness of gypsum specimens in a timedependent manner. Immersion of gypsum specimens in $\mathrm{SH}$ showed a bigger increase in surface roughness in a time-dependent manner than immersion in OZW and GL. We could not determine the reason why the surface roughness of New Fujirock immersed in disinfectants took minus values (Table 1) in our study.

Our study suggested that crystal grains of gypsum specimens immersed in $\mathrm{SH}$ tended to be more destroyed in a time-dependent manner compared with immersion in GL and SH (Fig. 3). These results are in good agreement with the trend of increasing surface roughness shown in Table 1 . Our results suggested that the difference in destruction of crystal grains depended on the type of disinfectants. We could not determine the reason why SEM observations (Fig. 3B) of Hybrid Rock immersed in GL were not in good agreement with DIF values (Table 1) in our study. There was no significant destruction of the crystal structure on the surface of gypsum specimens immersed in OZW in a timedependent manner (Fig. 4).

Ozone in water degrades to oxygen ${ }^{26)}$. Ozone decomposition in water decreases OZW concentrations. As a preliminary experiment, five pieces of gypsum specimens of a similar size in our study were immersed in $500 \mathrm{~mL}$ of OZW, and a decomposition test of OZW was performed. We found that $3 \mathrm{ppm}$ of OZW charged with the specimens reached $2.4 \mathrm{ppm}$ after $5 \mathrm{~min}, 2 \mathrm{ppm}$ after $10 \mathrm{~min}$, and $1.8 \mathrm{ppm}$ after $20 \mathrm{~min}$. OZW concentrations became approximately half by $20 \mathrm{~min}^{13)}$. These findings suggested that the reaction of gypsum material used in this study with OZW did not cause decomposition of OZW. In our study, the effect of disinfectant on the surface roughness of dental gypsum under static water was evaluated. The effect of rinsing with ultrapure water for $10 \mathrm{~s}$ on the surface roughness of gypsum specimens was less than $0.02 \mu \mathrm{m}$. We did not observe distinctly destroyed crystal structures on the gypsum specimen surface after rinsing with ultrapure water for $10 \mathrm{~s}$ with observation by SEM. OZW for disinfection of dental stone casts is an excellent disinfectant material. This can be expected to prevent further effects on surface roughness of the dental stone cast after disinfection because rinsing the dental stone cast after disinfection is not necessary to remove OZW. 
Previous study reported that using OZW for disinfection needs for $10 \mathrm{~s}^{16)}$ or $1 \mathrm{~min}^{20)}$. In clinical cases, it is not able to avoid that organic substances adhere on dental stone casts $^{1-3)}$. It has been known from previous experiments that most organic solutes (impurities) promote or inhibit the decomposition of ozone ${ }^{27)}$. Considering the above, further study must be necessary using the dental stone cast adhering organic matter to know proper OZW concentration, immersion time and OZW volume as a clinical application model.

\section{CONCLUSION}

Our results reveal that effects on the surface roughness of gypsum specimens immersed in OZW and GL are similar. These results indicate that the influence of crystal grains of gypsum specimens immersed in OZW or GL leads to milder erosion than $\mathrm{SH}$ immersion.

Because of the limitations of this study, the decomposition of OZW, the optimum OZW concentration, the volume of OZW, using the gypsum specimen adhering organic matter model and the disinfection time must be determined in future research. However, OZW is a useful candidate for relatively safe disinfection material for dental stone casts in contrast to conventional disinfection chemicals, such as $\mathrm{GL}^{14)}$ and $\mathrm{SH}$, in which there are concerns about their effects on the human body. There was no large difference in the surface roughness value among the 3 disinfectants used in this study.

\section{REFERENCES}

1) Gerhardt DE, Sydiskis RJ. Impression materials and virus. J Am Dent Assoc 1991; 122: 51-54.

2) ADA Council on Scientific Affairs and ADA Council on Dental Practice. Infection control recommendations for the dental office and the dental laboratory. J Am Dent Assoc 1996; 127: 672-680.

3) Kohn WG, Collins AS, Cleveland JL, Harte JA, Eklund KJ, Malvitz DM. Guidelines for infection control in dental health-care settings 2003. Centers for Disease Control and Prevention (CDC). MMWR Recomm Rep 2003; 52: 1-61.

4) Taylor RL, Wright PS, Maryan C. Disinfection procedures: their effect on the dimensional accuracy and surface quality of irreversible hydrocolloid impression materials and gypsum casts. Dent Mater 2002; 18: 103-110.

5) Rentzia A, Coleman DC, O’Donnell MJ, Dowling AH, O'Sullivan M. Disinfection procedures: their efficacy and effect on dimensional accuracy and surface quality of an irreversible hydrocolloid impression material. J Dent 2011; 39: 133-140.

6) Powell GL, Runnells RD, Saxon BA, Whisenant BK. The presence and identification of organisms transmitted to dental laboratories. J Prosthet Dent 1990; 64: 235-237.

7) Egusa H, Watamoto T, Abe K, Kobayashi M, Kaneda Y, Ashida $\mathrm{S}$, Matsumoto T, Yatani H. An analysis of the persistent presence of opportunistic pathogens on patient derived dental impressions and gypsum casts. Int J Prosthodont 2008; 21: 62-68.

8) Leung RL, Schonfeld SE. Gypsum casts as a potential source of microbial cross-contamination. J Prosthet Dent 1983; 49: 210-211.

9) Abdullah MA. Surface detail, compressive strength, and dimensional accuracy of gypsum casts after repeated immersion in hypochlorite solution. J Prosthet Dent 2006; 95: 462-468.

10) Ivanovski S, Savage NW, Brockhurst PJ, Bird PS. Disinfection of dental stone casts: antimicrobial effects and physical property alterations. Dent Mater 1995; 11: 19-23.

11) Lucas MG, Arioli-Filho JN, Nogueira SS, Batista AU, Pereira Rde P. Effect of incorporation of disinfectant solutions on setting time, linear dimensional stability, and detail reproduction in dental stone casts. J Prosthodont 2009; 18: 521-526.

12) Onizuka T, Kadokawa A, Matsushita Y, Jimi T. Effect of immersion in disinfectant solution on properties of die stone. Part 2. Dimensional change and reproduction of details. Jpn J Dent Mater 1996; 15: 369-378.

13) Rutala WA, Weber DJ, the Healthcare Infection Control Practices Advisory Committee (HICPAC). Guideline for disinfection and sterilization in healthcare facilities, 2008. Centers for Disease Control (CDC); 2008. p. 158. Available at https://www.cdc.gov/infectioncontrol/pdf/guidelines/ disinfection-guidelines.pdf. Accessed Nov 2017.

14) Takigawa T, Endo Y. Effects of glutaraldehyde exposure on human health. J Occup Health 2006; 48: 75-87.

15) Berg E, Nielsen O, Skaug N. High-level microwave disinfection of dental gypsum casts. Int J Prosthodont 2005; 18: 520-525.

16) Nagayoshi M, Fukuizumi T, Kitamura C, Yano J, Terashita M, Nishihara T. Efficacy of ozone on survival and permeability of oral microorganisms. Oral Microbiol Immunol 2004; 19: 240-246.

17) Filippi A. Water disinfection of dental units using ozonemicrobiological results after 11 years and technical problem. Ozone Sci Eng 2002; 24: 479-483.

18) Sobsey MD. Inactivation of health-related microorganisms in water by disinfection process. Wat Sci Tech 1989; 21: 179195.

19) Poulis N, Kyriacou A, Kotsou M, Bezirtzoglou E, Prombonas A, Drakoulis N. Effectiveness of low-flow high-ozone concentration disinfection of dental impressions: A comparative study to immersion disinfection. Br J Appl Sci Technol 2014; 4: 2528-2537.

20) Arita M, Nagayoshi M, Fukuizumi T, Okinaga T, Masumi S, Morikawa M, Kakinoki Y, Nishihara T. Microbicidal efficacy of ozonated water against Candida albicans adhering to acrylic denture plates. Oral Microbiol Immunol 2005; 20: 206210.

21) Ohkawa H, Tsuji M, Ohtsuki K, Ohnishi M, Akitsu T. Highdensity ozone disinfection of medical-care materials for dental surgery. Plasma Process Polym 2005; 2: 112-119.

22) Hall RM, Sobsey MD. Inactivation of hepatitis A virus and MS2 by ozone-hydrogen peroxide in buffered water. Wat Sci Tech 1993; 27: 371-378.

23) Bader H, Hoigne J. Determination of ozone in water by the indigo method; a submitted standard method. Water Res 1981; 15: 449-456.

24) Amin WM, Al-Ali MH, Al Tarawneh SK, Taha ST, Saleh MW, Ereifij N. The effects of disinfectants on dimensional accuracy and surface quality of impression materials and gypsum casts. J Clin Med Res 2009; 1: 81-89.

25) Onizuka T, Kamimura N, Kajiwara H, Nakashima A, Suenaga K, Jimi T. Influence of boiling water treatment on surface roughness and surface microstructure of set gypsum (dental stone). Dent Mater J 1995; 14: 245-255.

26) Souya I, Ozone Hand Book, first ed., Japan Ozone Association, Tokyo; 2004. p. 7-8.

27) Staehelin J, Hoigne J. Decomposition of ozone in water in the presence of organic solutes acting as promoters and inhibitors of radical chain reactions. Environ Sci Technol 1985; 19: 1206-1213. 